\title{
UN PROBABLE TALLER LOCAL DE CERÁMICA PINTADA TARDORROMANA EN TARANCUEÑA (SORIA)
}

\author{
JUAN MANUEL ABASCAL PALAZÓN \\ Universidad de Alicante
}

\begin{abstract}
Los hallazgos de cerámica pintada del yacimiento romano de Tarancueña (Soria), destacan por su homogeneidad temática y cronológica, así como por reunir en un solo enclave los tipos que aparecen en las regiones periféricas. El análisis del material, combinado con la información de las excavaciones, permite sugerir la existencia de un taller comarcal que produjo este tipo de piezas en la segunda mitad del siglo IV y los primeros años del siglo $\mathrm{V}$. d. $\mathrm{C}$.
\end{abstract}

The discovery of painted pottery in the Roman site of Tarancueña (Soria) stand out because of its tematic and chronological homegeneity, and the meeting in only one site of the types which appear in the periferic counties. The analysis of the material, combined with the information from the excavations, allows us to suggest the existence of a county factory which produced this type of pottery in the second half of the IVth Century A. D. and the first years of the Vth Century A. D.

El yacimiento romano de Tarancueña se comenzó a excavar en 1982 bajo la dirección de don Miguel López Vázquez y de don Miguel Palomero. Durante los trabajos de aquella campaña apareció un gran conjunto de cerámica pintada con cronología tardorromana al igual que el resto de los materiales del enclave, cuyo estudio y publicación nos fue amablemente confiado por sus excavadores, quienes, estando aún los trabajos en curso y a la espera de una publicación global de los mismos, han tenido la gentileza de permitirnos dar a conocer aquí el lote de cerámica pintada que presentamos; por todo ello, nuestro agradecimiento. Cinco de las piezas presentadas ahora fueron incluidas ya en nuestro trabajo sobre las producciones peninsulares (ABASCAL 1986 , n. ${ }^{\circ} 700,702,743,767$ y 774), pero se analizan ahora dentro de su propio ambiente a la luz del conjunto de los hallazgos.
El total del hallazgo de cerámica pintada de Tarancueña de la mencionada campaña de 1982 comprende más de 300 fragmentos, de los que aproximadamente 100 son útiles para el estudio de decoraciones y formas, aunque sólo hemos reproducido una pequeña parte. Para su estudio tipológico seguimos nuestra propia tabla de formas (ABASCAL 1986, Figs. 169 y 170).

En el yacimiento aparecen básicamente cinco tipos de' recipientes: Jarras de boca ancha y pico (forma 22), vasos bitrococónicos carenados (forma 23), cántaros (forma 24), morteros de labio vuelto (forma 25) y jarras carenadas (forma 31 ). La proporción de todas estas formas no es idéntica entre los hallazgos, siendo destacadamente mayoritario el tipo de vasos bitroncocónicos carenados, de los que se han podido reconocer fragmentos de unos 50 ejemplares diferentes; por su cantidad le siguen en 


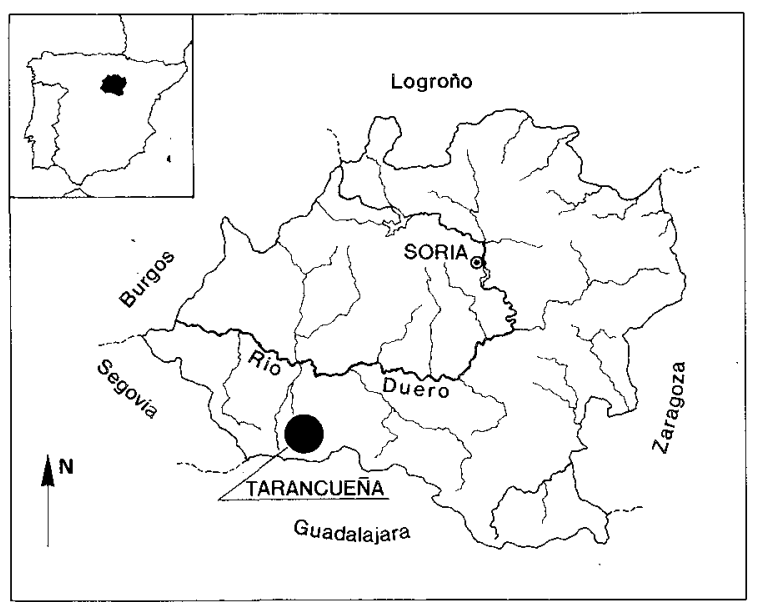

Fig. 1.-Plano de situación del yacimiento.

importancia las jarras de la forma 22 , con más de 25 ejemplares, estando escasamente representados los otros tres tipos, con sólo dos ejemplares cada uno. Afortunadamente ha sido posible reconstruir una pieza de cada forma, pese a la gran fragmentación de los hallazgos.

Aunque en la excavación se pudo establecer una sucesión estratigráfica, la coincidencia entre fragmentos de distintas áreas de la misma, así como la uniformidad técnica y estilística entre las mismas, sugiere que la zona conocida pueda ser un vertedero del enclave, como nos han sugerido amablemente sus excavadores. En este sentido debe tenerse en cuenta que entre la acumulación de piezas del lugar figura un importantísimo conjunto de TSH tardía, cerámica común, objetos metálicos, monedas, etc. Ahora bien, frente al teórico carácter acumulativo del hallazgo, las piezas muestran una gran uniformidad cronológica, probablemente por haber sido muy reducido el margen de utilización del lugar y, una vez más, hay que lamentar no poder dar una cronología precisa ni una seriación temporal de los motivos, debiéndonos conformar con la datación proporcionada por las monedas de Honorio halladas en el yacimiento, que apuntan un teórico límite superior de comienzos del siglo V para los hallazgos.

Una vez vistas las características generales del lugar y de los hallazgos, nos referiremos a las peculiaridades formales y estilísticas de cada una de las variedades como paso previo a su valoración.

Jarras de boca ancha y pico (forma 22), (figs. 2, 3 y 4). La jarra es el recipiente para líquidos con mayor grado de dispersión en los yacimientos tar-
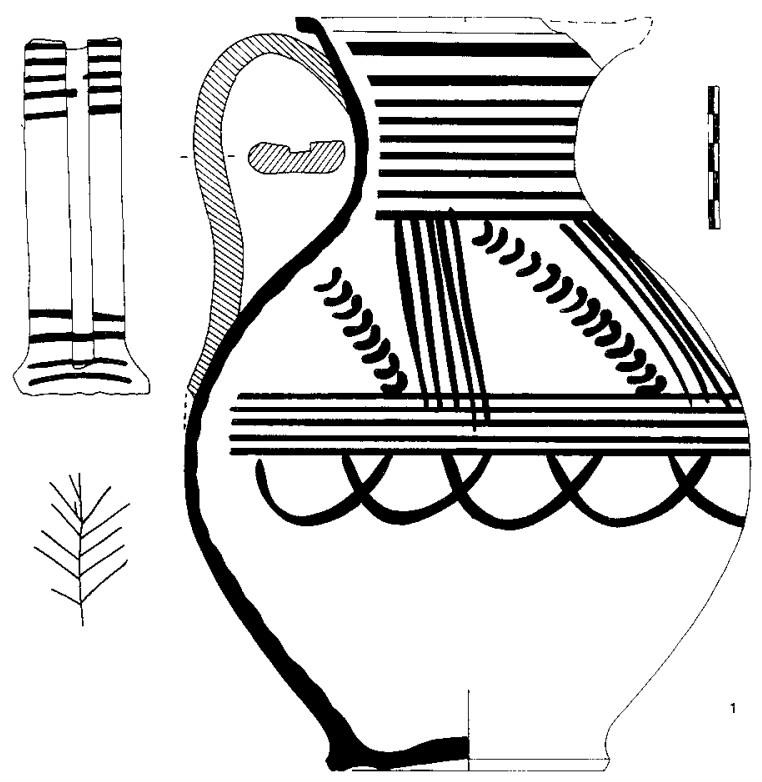

Fig. 2.-Jarra de la forma 22.

dorromanos de la Meseta norte y en la zona de contacto con la Meseta sur. Se presenta con múltiples variantes de modelación y estilos decorativos, lo que justifica su distribución en diferentes grupos, de los que éste es el más numeroso. Todos los ejemplares de Tarancueña pertenecen a esta variante. Ni en el conjunto del tipo ni en los hallazgos de este yacimiento concurren idénticas decoraciones, siendo éstas casi tan diversas como el número de piezas, aunque se pueden establecer una serie de categorías básicas: el esquema general presenta un friso decorado en el hombro, de anchura variable, metopado por grupos de líneas paralelas y flanqueado por fajas horizontales en cuello y panza; tras la inflexión de ésta, y en el punto en que el diámetro de la pieza comienza a disminuir hacia el pie, la decoración se remata con una serie de arcos invertidos entrecruzados generalmente (fig. $2, \mathrm{n}^{\circ}{ }^{\circ}$, fig. $3, \mathrm{n}^{\circ}{ }^{\circ}$ ), aunque no faltan composiciones más esquemáticas (fig. 3, n. ${ }^{\circ} 4$ ).

Por su singularidad, hay que destacar la decoración de la jarra n. ${ }^{\circ} 1$ (ABASCAL 1986, n. ${ }^{\circ} 700$ ), cuya decoración central son series oblicuas de trazos curvos, y que junto a la n. ${ }^{\circ} 2$ (ABASCAL 1986, n. ${ }^{\circ}$ 702) ejemplifica los estilos más representativos de decoraciones. Precisamente en esta pieza $n .^{\circ} 2$ aparecen los roleos, muy frecuentes en el yacimiento y presentes también en Los Tolmos de Caracena, 

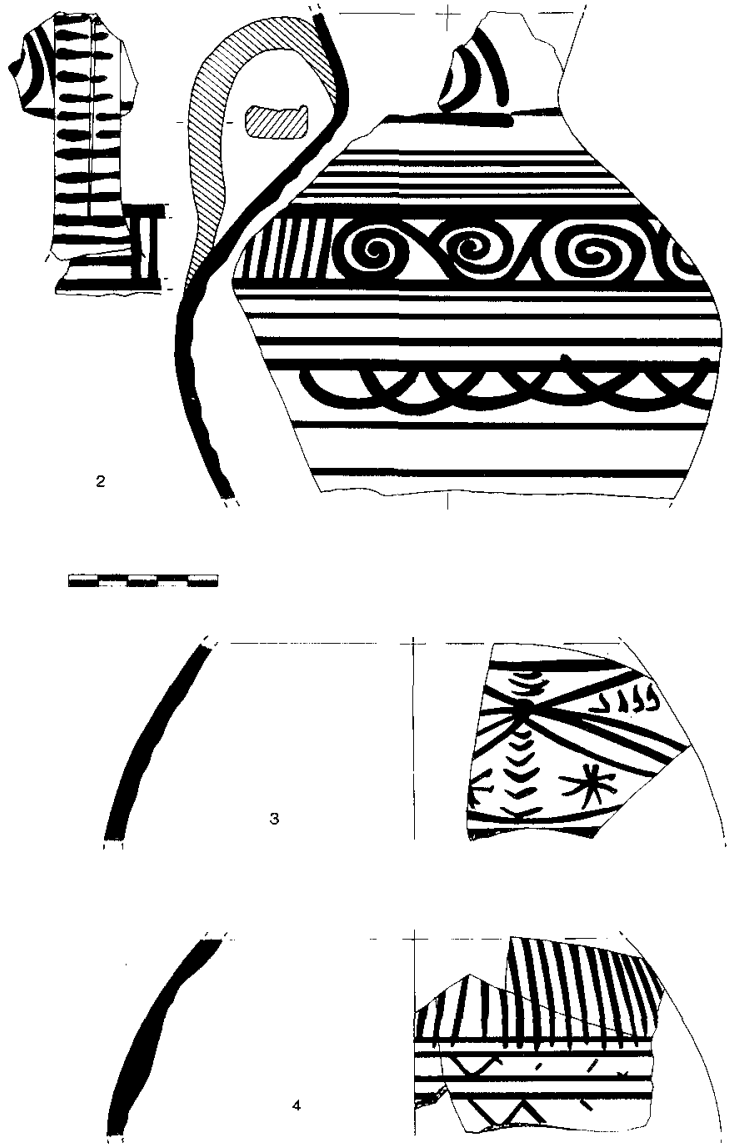

Fig. 3.-Jarra y fragmentos de la forma 22.

a corta distancia de Tarancueña (JIMENO 1979, lám. VII, 7), en El Quintanar (Bayubas de Abajo, Soria) (GARCÍA MERINO 1967, tabla VI, 61), Tiermes (ARGENTE et alii 1984, fig. 112, 79-373), etc., por citar sólo algunos yacimientos sorianos. Estos roleos son temas característicos de las decoraciones de estas piezas, pero no exclusivos de esta forma. Otro de los temas habituales son las estrellas, como las que figuran en las piezas $n .^{\circ} 3,8$ y 11 , presentes también en los yacimientos antes citados, así como en Zaragoza (ABASCAL 1986, n. ${ }^{\circ} 701$ ), Coca (Segovia) (MOLINERO 1971, 75, n. ${ }^{\circ} 2679$ ), Alcalá de Henares (FERINÁNDEZ-GALIANO 1984, n. ${ }^{\circ} 106$, ABASCAL 1986, n. ${ }^{\circ} 708$ ) con otros muchos ejemplos, etc., por citar únicamente testimonios sobre esta forma, ya que en otras variantes tipológicas el motivo es también usual.

En el hombro se registran en ocasiones composiciones en forma de aspa, como ocurre con la pieza

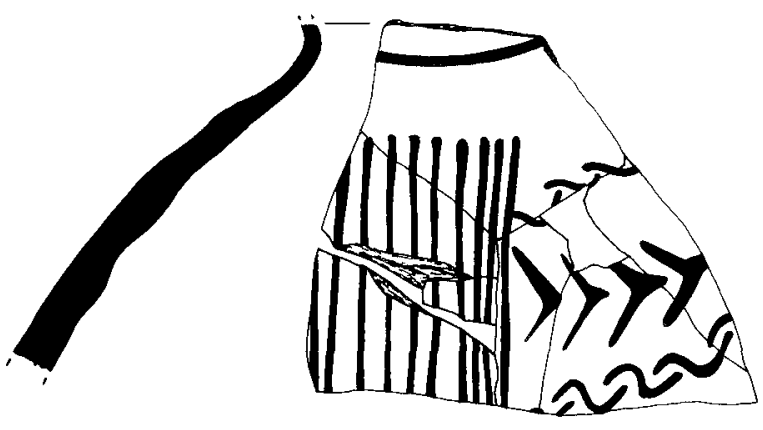

5

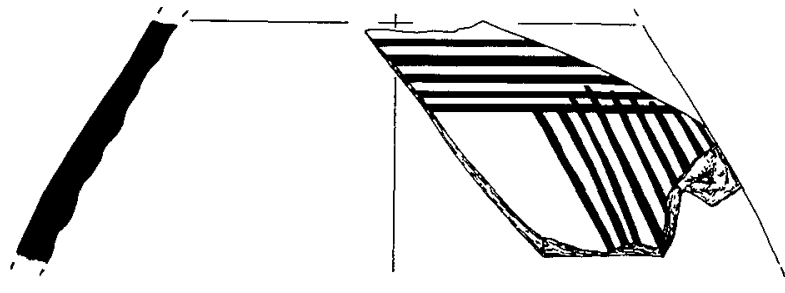

6
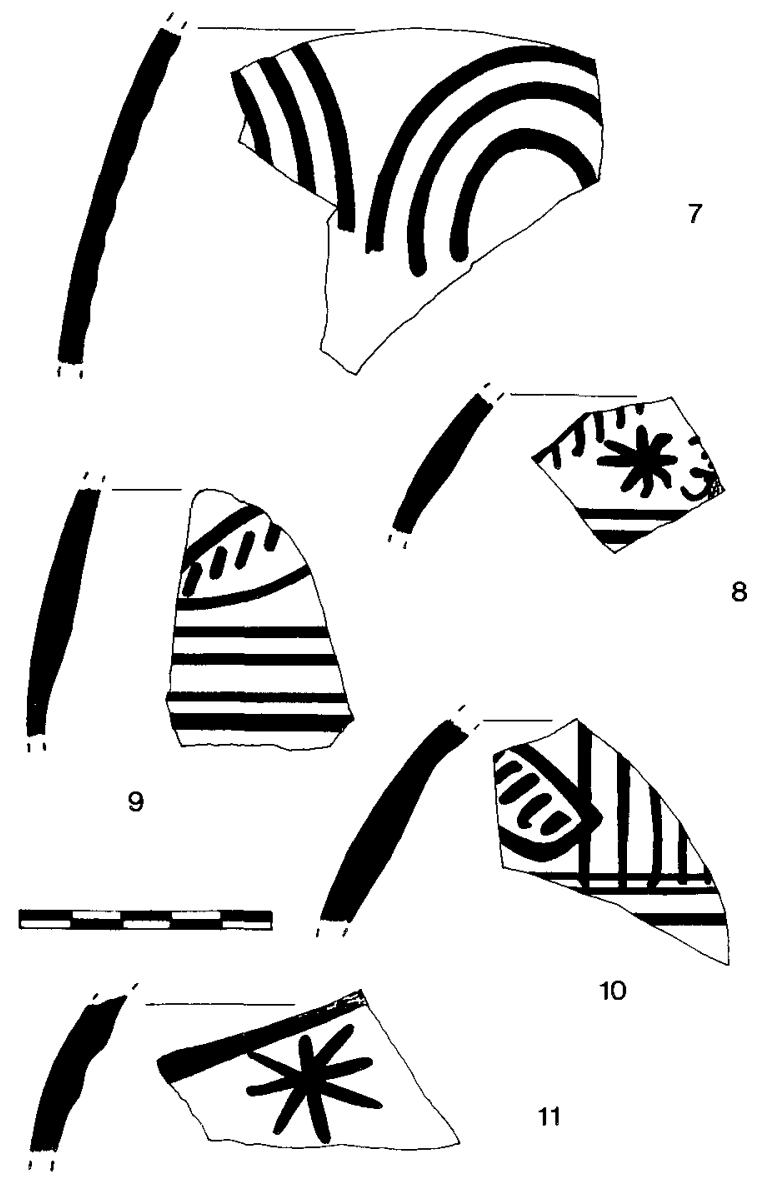

10

Fig. 4.-Fragmentos de jarra de la forma 22. 


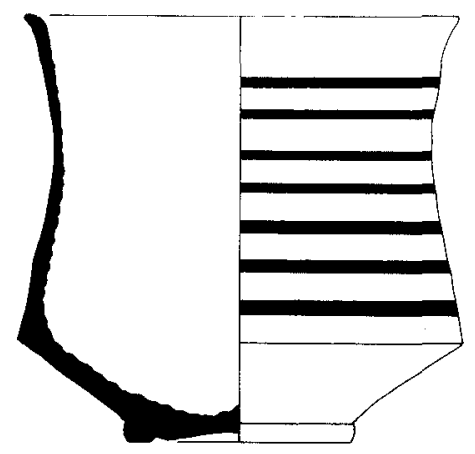

n. ${ }^{\circ} 3$ o como parecen evidenciar los fragmentos 9 y 10 , aunque el tipo es más escaso, y sigue principalmente esquemas altoimperiales de los talleres de la Meseta norte.

Por su relativa escasez merece consignarse la decoración en campo abierto a la que parece remitir el fragmento $n .{ }^{\circ} 7$, así como la composición con series de puntas de flecha y $S S S$ entrelazadas del n. ${ }^{\circ}$, presente en enclaves como Los Tolmos de Caracena o El Quintanar.

Vasos bitroncocónicos carenados (forma 23),

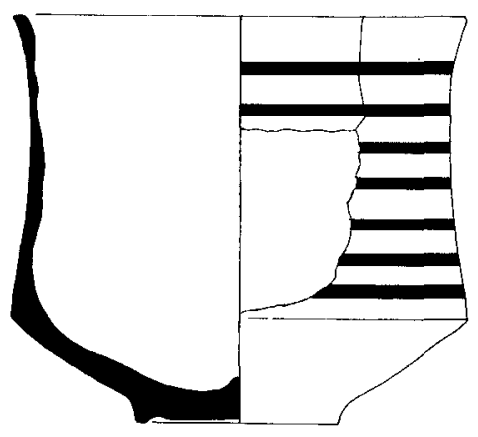
(figs. 5, 6 y 7). Es la forma más común en el yacimiento al tiempo que una de las habituales en los enclaves tardorromanos de la Meseta. La pasta de todos los ejemplares varía entre el naranja y el rojo ladrillo, siendo escasa una producción en pasta blanquecina como la del $n .^{\circ} 25$. Aunque manteniendo las proporciones, el tamaño de los ejemplares conservados varía ligeramente, especialmente en el diámetro de la boca, que oscila entre 7 y $12 \mathrm{cms}$., con excepciones señaladas como la del $n .^{\circ} 25$, cuya diferencia de pasta sugiere un planteamiento distinto dentro de la misma forma.

La principal característica de estos vasos en Tarancueña es su cocción fuertemente oxidante y lo acusado de sus líneas de torno, a lo que habría que añadir las reducidas dimensiones de un gran número de piezas.

La decoración en todos los casos es de color negruzco, pintada con el torno en movimiento y pintura muy diluida. Cuando, por su tamaño, el recipiente debe llevar asas, éstas se colocan después de pintar la pieza, tapando así parte de la decoración, como ocurre con el $n .^{\circ} 23$. Estas asas no debían ser muy frecuentes, pues han aparecido en cantidad muy reducida si se compara con el número de vasos; van decoradas al exterior con los mismos trazos negruzcos horizontales, aunque en una ejecución más descuidada (n. ${ }^{\circ}$ 26). Fuera de Tarancueña es usual la presencia de doble asa en la mayor parte de los ejemplares (ABASCAL 1986, 202).

Se conservan tan sólo dos piezas completas (n. ${ }^{\circ}$ 16 y 17), de dimensiones similares, en las que las características de composición y cocción concuerdan con exactitud. Dentro de la relativa homogeneidad de los ejemplares hallados merecen citarse las variaciones que se producen en la inclinación de la pared y forma del borde: estas variaciones hacen que el cuerpo superior del vaso oscile entre la forma de cubilete (n. $\left.{ }^{\circ} 24\right)$ y la de huso (n. $\left.{ }^{\circ} 16\right)$, pudién- 
dose encontrar bordes con labio más o menos afilado.

Frente a la habitual decoración de líneas horizontales que presentan casi todos los ejemplares, hay que citar el tema ajedrezado del n. ${ }^{\circ} 25$, también presente en piezas no ilustradas, así como reticulados entre líneas paralelas, escasos en el yacimiento, pero bien conocidos en otros enclaves de la Meseta, incluido el cercano Tiermes (ARGENTE et alii 1984, fig. 110, 80-788).

Excepción hecha de las citas características propias de los vasos de este yacimiento, el resto de sus elementos formales y decorativos aparecen representados en diferentes enclaves. La pieza más significativa de esta forma procede de Hortezuela de Océn (Guadalajara), de comienzos del siglo IV (LÓPEZ ROA 1980, fig. 9), habiéndose encontrado un gran número de ejemplares en Alcalá de Henares (FERNÁNDEZ-GALIANO 1984, passim, ABASCAL 1986, n. ${ }^{\circ} 750$ ss.) con forma de cubilete; la forma se conoce también en Los Tolmos de Caracena (Soria) (JIMENO 1979, Lám. VII, 4), Baños de Valdearados (ARGENTE 1979, passim), Getafe (Madrid) (PRIEGO 1980, fig. 46), Hita (Guadalajara) (ABASCAL 1986, 203), Gárgoles de Arriba (Guadalajara) (ibid. pág. cit.) y Villaverde (Madrid) (ABASCAL 1984a, n. ${ }^{\circ} 48,1986, n .^{\circ} 759$ ). La pieza más antigua de las conocidas procede de Clunia, hallada en el piso de la habitación $n .^{\circ} 35$ del «palacio» excavado por Taracena, con una cronología de mediados del siglo III, a juzgar por los hallazgos numismáticos (ABASCAL 1986, n. ${ }^{\circ} 741$ ). La mayor fase de desarrollo del tipo se alcanza a lo largo del siglo IV, y especialmente en su segunda mitad, como prueban las estratigrafías de Alcalá de Henares (FERNÁNDEZ-GALIANO 1984, passim), obteniéndose las cronologías terminales en Tarancueña, con monedas de Honorio, y los Tolmos de Caracena, con una moneda de Arcadio acuñada en Tréveris (388-392), que fecha el conjunto a finales del siglo IV.

Cántaros (forma 24), (fig. 8). El cántaro, aunque representado sólo por dos ejemplares de Tarancueña, es también una forma común a otros yacimientos de la Meseta. Su gran tamaño es probablemente la causa de que sólo se conserve un ejemplar intacto, el de Gallur (Zaragoza) (BELTRÁN 1957, 191 y lám.). Todas las piezas conocidas presentan únicamente decoración en el hombro, con grandes motivos geométricos, mientras que toda
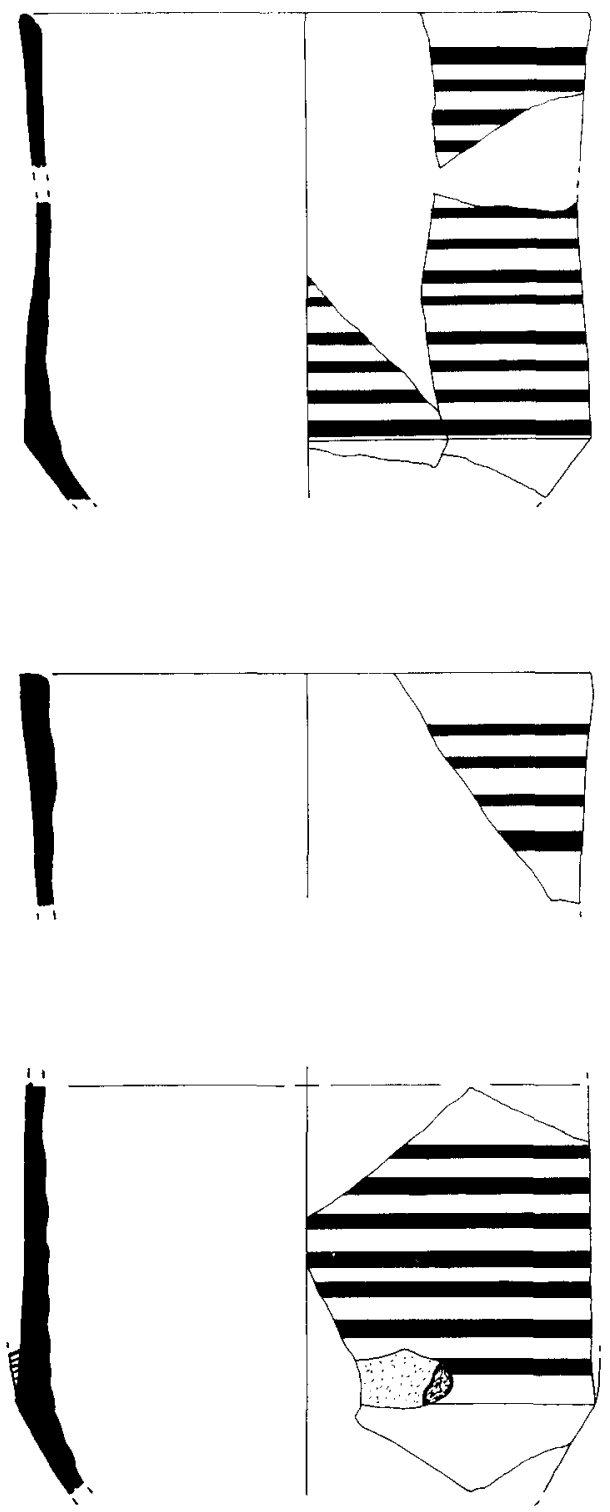

23

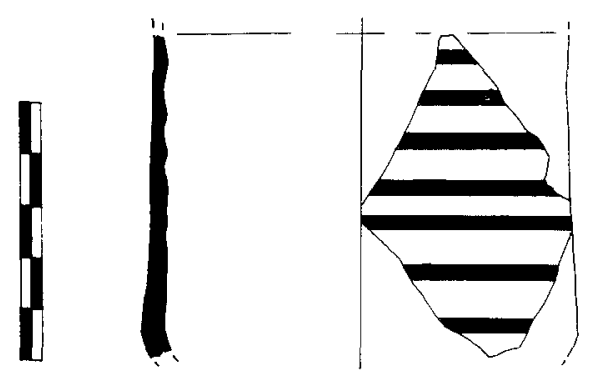

Fig. 6.-Fragmentos de vasos de la forma 23 . 

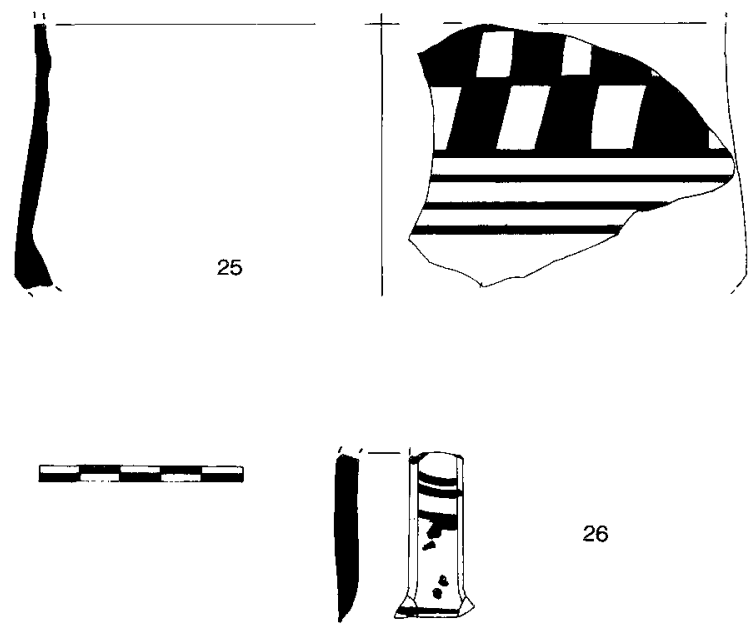

26

Fig. 7.-Fragmentos de vaso y asa de la forma 24 .

la pared de la vasija se conserva lisa hasta alcanzar la base, que es umbilicada y estrecha, evidentemente inútil para mantener el recipiente en equilibrio, pues éste debía sostenerse encajado sobre una estructura de madera como en la actualidad.

De los dos ejemplares conservados en Tarancueña sólo uno está casi completo $\left(\mathrm{n}^{\circ}{ }^{\circ} 27\right)$, y la ausencia de la embocadura puede suplirse con los paralelos de Gallur (BELTRÁN 1957, 191) ó La Pesquera (Zaragoza) (PAZ PERALTA 1980, 340, Lám. VI, 26). Presenta esta pieza un friso horizontal decorado con aspas de apéndices separadas por escaleras verticales y con roleos en los espacios libres; este tema de aspas es habitualmente altoimperial, aunque conocemos otro ejemplar tardío en Quintanaurría (OSABA et alii 1971, 187, fig. 3); por lo que se refiere al tema de la escalera, es una de las aportaciones del mundo de la sigillata tardía a las cerámicas pintadas, aunque es rara esta disposición en línea recta, paralelizable sólo en ejemplares de Alcalá de Henares (FERNÁNDEZ-GALIANO 1984 , Dehesa 1977, n. $^{\circ} 103$ y 136) y Casa del Cerro (Madrid) (ABASCAL 1984a, n. 92 y 1986, n. $\left.{ }^{\circ} 777\right)$. Lo usual es que la escalera forme un semicírculo, como ocurre tanto en fragmentos de cántaros pintados como en otras formas precedentes de Coca (Segovia) (MOLINERO 1971, 75, n. 2679), Velamazán (Soria) (REVILLA 1985, fig. 136, n. ${ }^{\circ} 33$ ), Los Tolmos de Caracena (Soria) (JIMENO 1979, Lám. VII, 2), Alcalá de Henares (FERNÁNDEZ-GALIANO 1984, Dehesa 1977, $n{ }^{\circ}$ 233) y Hornillos del Camino (Burgos) (MAR-
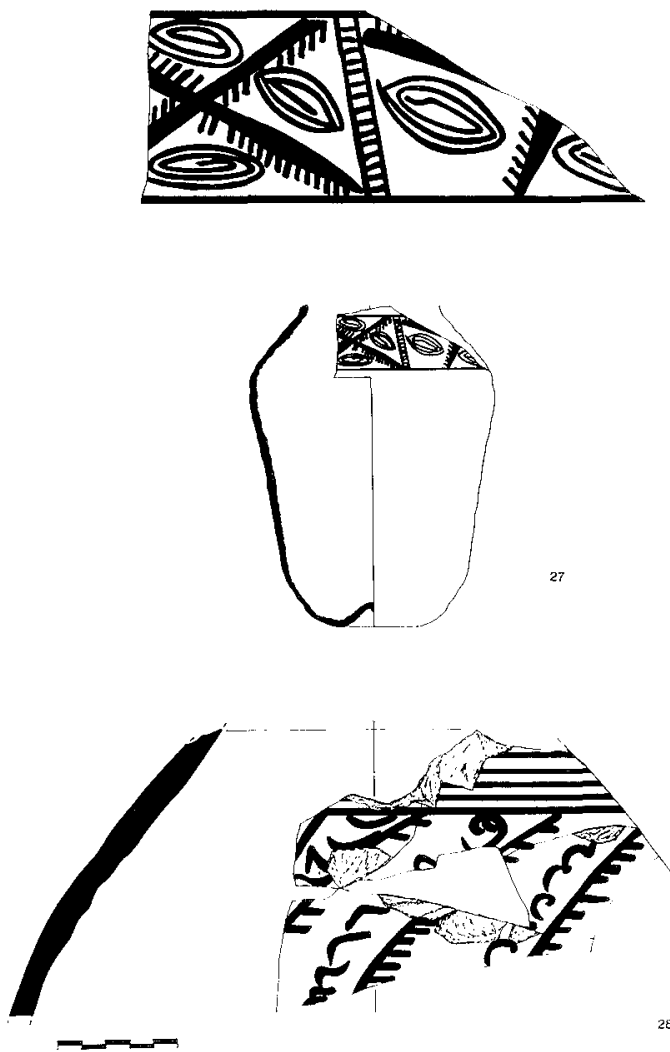

Fig. 8.-Cántaro completo y fragmento de la forma 24 .

TÍNEZ BURGOS 1946, 76, n。 1 y Lám. XIX, 2). Del segundo ejemplar de cántaro hallado en este yacimiento (n. ${ }^{\circ} 28$ ), sólo se conserva parte del hombro que, aunque fracturado, permite distinguir series alternas de trazos y líneas de apéndices, todo en color negruzco, en una composición para la que no conocemos paralelos.

La fecha de los tipos de Tarancueña a finales del siglo IV coincide con el margen de los niveles de Alcalá de Henares (siglo IV) y el contexto de Gallur (fines del siglo IV), por lo que la cronología de la forma se puede establecer, sin duda, a lo largo de todo este siglo.

Morteros de labio vuelto (forma 25), (fig. 9). Este tipo de mortero no es frecuente en la Meseta norte, con sólo tres piezas conocidas: una en Pamplona (MEZQUIRIZ 1978, 114, ABASCAL 1986, n. $\left.{ }^{\circ} 775\right)$ y estas dos de Tarancueña. En este yacimiento los morteros presentan las mismas características de pasta y coloración que el resto de las piezas encontradas. Están decorados con series de 


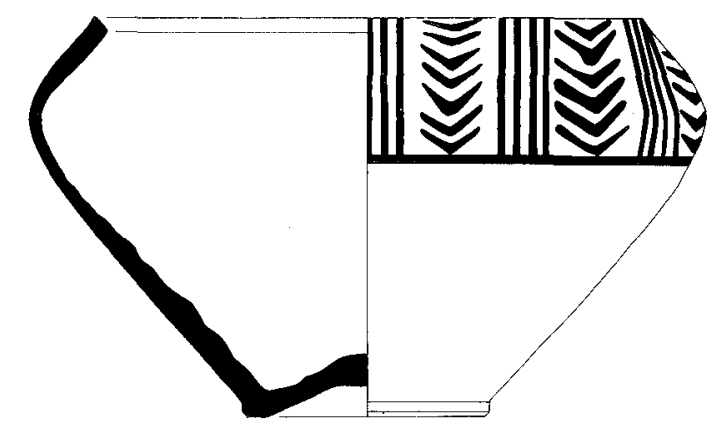

29

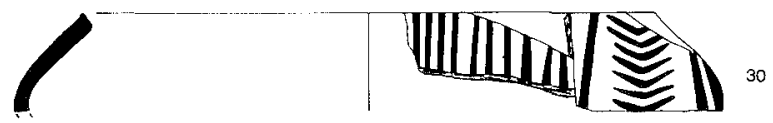

Fig. 9.-Mortero y fragmento de la forma 25.

puntas de flecha separadas por líneas verticales, formando un friso a lo largo del hombro, en una composición indudablemente tomada de la sigillata tardía y que raramente se documenta con tal exactitud, si exceptuamos la botella del castro de Yecla (Burgos) (GONZÁLEZ SALAS 1945, Lám. X y XI), desgraciadamente desaparecida en el incendio del monasterio de Santo Domingo de Silos. Este tipo de mortero no es rastreable siquiera en otros pequeños fragmentos de Tarancueña, aunque, además del testimonio ya citado de Pamplona, lo encontramos en la Meseta sur, con hallazgos en Alcalá de Henares (ABASCAL 1986, n. ${ }^{\circ} 776,778$ y 779) y Casa del Cerro (Madrid) (ABASCAL 1986, n. ${ }^{\circ} 777$ ). Todos los ejemplares se fechan a lo largo del siglo $\mathbb{I V}$.

Jarras carenadas (forma 31), (fig. 10). Es éste un extraño tipo de jarra cuya difusión en la Meseta debió ser escasa a juzgar por el reducido número de ejemplares conocidos. Durante años, una jarra de esta forma hallada en Santervás del Burgo (Soria), (ORTEGO 1954-55 fig. 67 y 1959, fig. 3) fue considerada como un ejemplar atípico por su rareza, si bien hoy día conocemos al menos otros tres ejemplares, los dos de Tarancueña $\left(n .^{\circ} 31\right.$ y 32$)$ y otro de Tiermes (ARGENTE et alii 1984, Fig. 111, 801030); desgraciadamente, la única cronología segura que tenemos para el tipo es la proporcionada por Tarancueña para finales del siglo IV, pues la pieza termestina procede de un relleno.
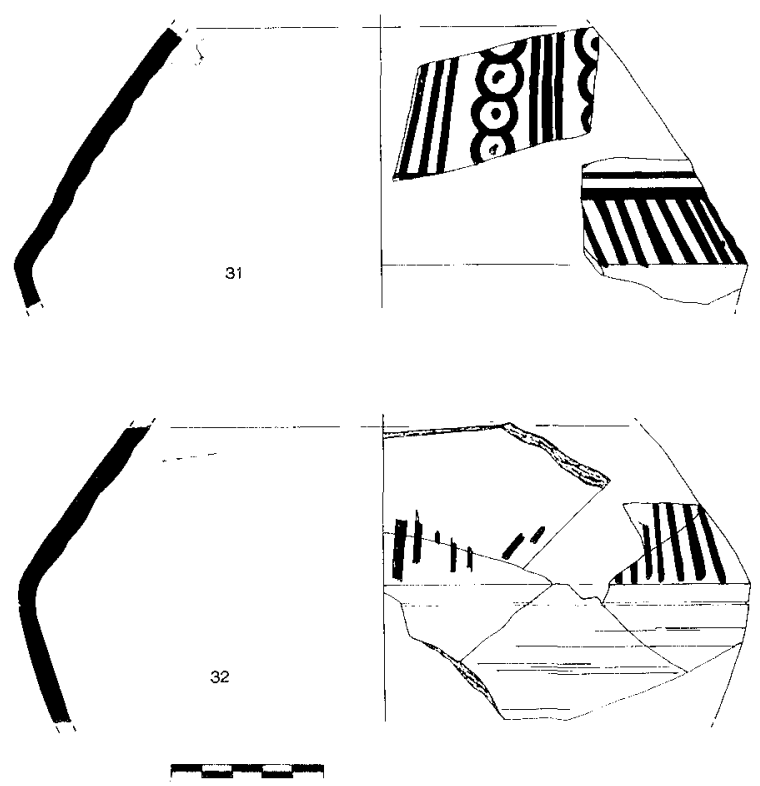

Fig. 10.-Fragmentos conservados de jarras carenadas de la forma 31 .

Con respecto a la decoración, cada uno de los yacimientos citados presenta en sus piezas un estilo propio, coincidente en los dos ejemplares de Tarancueña a pesar del diferente grado de conservación: sobre la carena figuran trazos paralelos que limitan un friso en el que aparecen círculos tangentes formando series con separación de líneas paralelas. Este tipo de círculos sólo aparece hasta la fecha en la mitad sur de la provincia de Soria, y es probablemente uno de los estilos relacionables con un centro productor en Tarancueña; los paralelos estilísticos conocidos hasta la fecha proceden de Almarail (Soria) (BOROBIO 1985, fig. 8, n. ${ }^{\circ} 33$ ) y Tiermes (ARGENTE et alii 1984, fig. 108, 80-777), ambos probablemente sobre vasos bitrococónicos de la forma 23.

\section{VALORACIÓN DEL CONJUNTO}

Tarancueña debe considerarse como un eslabón más en la cadena de yacimientos que registran una ocupación plena en el siglo IV tras las destrucciones debidas a la crisis del siglo III; su particularidad dentro del conjunto se manifiesta en la ausencia de un nivel de ocupación altoimperial (al que sólo remiten escasos fragmentos pintados de superficie), en contraste con el panorama característico de villae 
como Dueñas (Palencia) (REVILLA et alii 1962), Prado (Valladolid) (WATTEMBERG 1962), Santervás del Burgo (Soria) (ORTEGO 1954-55 y 1959) o Los Quintanares de Rioseco (Soria) (ORTEGO 1976); en estos yacimientos aparece habitualmente una fase altoimperial que se interrumpe a mediados del siglo III, con evidentes síntomas de destrucción, y a comienzos del siglo IV se procede a su reconstrucción, con una nueva fase de hábitat pleno. Este fenómeno de potenciación de los grandes conjuntos rurales tras las invasiones del siglo III (BALIL 1957; BLÁZQUEZ 1964, 1968 y 1973; PALOL 1978; TARACENA 1950; TARRADELL 1955, 1957 , entre otros) es en la Meseta un proceso general al que acompañan nuevas manifestaciones culturales, entre las que hay que citar las cerámicas pintadas, cuya dispersión hoy día se muestra como un proceso generalizado en los ambientes de la época.

Dos son los tipos de yacimientos que presentan hallazgos de cerámica pintada tardía en la región: las necrópolis y los conjuntos habitados. No es éste el lugar apropiado para realizar un prolijo inventario de estos enclaves (en general, ABASCAL 1986, fig. 4), pero hay que significar el mayor número de los primeros, vinculados al panorama cultural que se ha dado en llamar «necrópolis del Duero». Por lo que se refiere a los más escasos testimonios de hábitat con cerámicas pintadas, en su mayoría nos abocan a los últimos momentos del siglo IV y principios del V, como ocurre en la propia Tarancueña con sus monedas de Honorio, Los Casarejos en San Martín de Losa (Burgos) (ABASOLO 1983), Santervás del Burgo (Soria) (ORTEGO 1954-55) o Baños de Valdearados (Burgos) (ARGENTE 1979).

Las cerámicas pintadas halladas en todos estos yacimientos evidencian una mayor relación con las necesidades de uso cotidiano, adaptando a ello sus formas y alejándose de los tipos suntuarios de períodos anteriores. Es ahora cuando las decoraciones clunienses con todo su barroquismo desaparecen y cuando los motivos evolucionan hacia esquemas elementales, siendo su presencia en las piezas consecuencia directa de una tradición fuertemente arraigada en la región que, olvidando los esquemas clásicos, produce tipos de baja calidad técnica, con composiciones tomadas del mundo de la sigillata y de las especies importadas (nótese en este sentido la relación entre los tipos de la forma 28 de Rigoir y la botella del castro de Yecla). Este relativo descenso de calidad de las producciones pintadas hace que ahora dejen de ser consideradas como un relati- vo producto de lujo y pasen a equipararse con el resto de las cerámicas comunes. Sólo algunas piezas muestran ahora esquemas ciertamente originales, mientras que el resto cubre sus frisos con geometrismos trazados de forma más o menos descuidada en los que parece estar ausente un deseo de superación estética.

Dentro de las producciones bajoimperiales de la Meseta norte, ya establecimos recientemente dos categorías distintas generadas en función del medio geográfico (ABASCAL 1984b y 1986, 154). Al segundo de los grupos entonces establecidos, el enraizado en la tradición celtíbera, habría que adscribir las producciones de Tarancueña, que, pese a su aparente homogeneidad cultural y a su contemporaneidad, se desligan así de conjuntos como los de Fuentespreadas (Zamora) (CABALLERO 1974) o Las Merchanas (Salamanca) (MALUQUER 1968).

Carecemos de evidencias arqueológicas para hablar de centros de fabricación de cerámicas pintadas en esta época en la Meseta. Hasta el presente sólo es posible fijar una serie de estilos diferenciados y pensar que obedecen a talleres distintos, la mayor parte de los cuales debieron estar ubicados en las villae, con una producción limitada a las propias necesidades de funcionamiento interno. La utilización de estos criterios estéticos debe ser extremadamente cautelosa, pues, pese al individualismo de las producciones, son muchos los motivos decorativos que comparten todos los centros (roleos, aspas, escaleras, semicírculos, etc.) y tan sólo en las composiciones de estos elementos se encuentran las verdaderas diferencias (ABASCAL 1986, 157).

En este panorama, Tarancueña se perfila como uno de los centros que, presumiblemente, tuvo producción propia. No hay resto alguno de hornos en el yacimiento hasta el presente, pero sus hallazgos muestran peculiaridades decorativas y esquemas que no conocemos en otros enclaves; a ello debe unirse el gran número de piezas de las formas 22 y 23 halladas en las excavaciones, en cantidad muy superior al promedio de otros núcleos, así como el hecho de que sea Tarancueña el único lugar excavado en la Meseta norte en el que estén presentes cinco formas cerámicas (jarra, jarra carenada, vaso bitroncocónico, cántaro y mortero), que sólo de forma ocasional aparecen en el resto de los enclaves. La ocupación del lugar parece cubrir al menos la segunda mitad del siglo IV d. C., y su existencia debe ponerse en relación con el panorama general de establecimientos rurales de gran extensión que conocemos 
para el período en la provincia de Soria y, concretamente, en esta comarca, en donde a los hallazgos tardíos de Tarancueña deben sumarse los de Tiermes y Los Tolmos de Caracena, cuya proximidad geográfica dibuja un panorama muy homogéneo.

\section{BIBLIOGRAFÍA}

ABASCAL, J. M. 1984a, «La cerámica pintada romana del Museo municipal de Madrid», en Estudios de Prehistoria y Arqueología madrileñas 3, 75-157.

- 1984b, «La cerámica pintada romana en Portugal y sus conexiones periféricas», en Revista de Guimarâes XCIV, 197-208.

- 1986, La cerámica pintada romana de tradición indígena en la Península Ibérica. Madrid.

ABÁSOLO, J. A. 1983, «Excavaciones en San Martín de Losa (Burgos)», en $N A H$ 15, 23lss.

ARGENTE, J. L. 1979, La villa tardorromana de Baños de Valdearados (Burgos). EAE 100. Madrid.

ARGENTE, J. L. et alii 1984, Tiermes II. EAE 128. Madrid.

BALIL, A. 1957, «Las invasiones germánicas en Hispania durante la segunda mitad del siglo III d. C.», en Cuadernos de Trabajos de la Escuela española de Historia y Arqueología en Roma IX, 97-143.

BELTRÁN, A. 1957, «Notas sobre el Cabezuelo de Gallur (Zaragoza)», en IV CNA, Zaragoza, 189ss.

BLÁZQUEZ, J. M. ${ }^{2} 1964$, Estructura económica y social de Hispania durante la anarquía militar y el Bajo Imperio; Cuadernos de la Cátedra de Historia Antigua de España. Madrid.

- 1968, «La crisis del siglo III en Hispania y Mauritania Tingitana», en Hispania XXVIII, 23-34.

- 1973, «El Imperio y las invasiones desde la crisis del siglo III al año 500», en Historia económica y social de España I, La Antigüedad, Madrid, 329-450.

BOROBIO, M. ${ }^{a}$ J. 1985, Carta arqueológica de Soria: Campo de Gómara. Soria.

CABALLERO, L. 1974, La necrópolis tardorromana de Fueniespreadas (Zamora). EAE 80. Madrid.

FERNÁNDEZ-GALIANO, D. 1984, Complutum I. EAE 137. Madrid.

GARCÍA MERINO, C. 1967, "Tres yacimientos de época romana inéditos en la provincia de Soria», en $B S A A$ XXXIII, 167-200.
GONZÁLEZ SALAS, 1945, El castro de Yecla en Santo Domingo de Silos, Informes y Memorias 7, Madrid.

JIMENO, A. 1979, «Aportación al estudio de las necrópolis del Duero: Los Tolmos de Caracena (Caracena-Soria)», en Revista de Investigación del Colegio Universitario de Soria III, 1, 91-105.

LÓPEZ ROA, C. 1980, «Yacimiento romano de Hortezuela de Océn, campaña de $1977 »$, en $N A H$ 9, 383-400.

MALUQUER, J. 1968, «Excavaciones arqueológicas en el castro de Las Merchanas (Lumbrales-Salamanca)», en Pyrenae IV, 101-128.

MARTÍNEZ BURGOS, M. 1946, «Adquisiciones del Museo Arqueológico de Burgos», en "Memorias de los Museos Arqueológicos provinciales VII, 75-77.

MEZQUIRIZ, M. ${ }^{a}$ A. 1978, Pompaelo II. Pamplona.

MOLINERO, A. 1971, Aportaciones de las excavaciones y hallazgos casuales (1941-1959) al Museo arqueológico de Segovia. EAE 72. Madrid.

ORTEGO, T. 1954-55, «Excavaciones en la villa romana de Santervás del Burgo (Soria)», en $N A H$ III-IV, 169-194.

- 1959, «La villa romana de Santervás del Burgo (Soria)», en VI CNA, 219-229.

- 1976, «Excavaciones arqueológicas realizadas en la villa romana de los Quintanares de Rioseco de Soria, en $N A H$, Arqueología 4, 359-373.

OSABA, B. et alli 1971, «La cueva de Quintanaurría, provincia de Burgos", en $N A H \mathrm{XV}, 179-188$.

PALOL, P. de, 1979, «El Baix Imperi». Historia de Catalunya I. Barcelona, 239-256.

PAZ PERALTA, J. 1980, «Una villa tardorromana en La Pesquera (Tarazona, Zaragoza)», en Turiaso I, 327ss.

PRIEGO, M. ${ }^{a}$ C. 1980 , «Excavaciones en la necrópolis de El Jardinillo (Getafe, Madrid)», en Revista de la Biblioteca, Archivo y Museo del Ayuntamiento de Madrid VII-VIII, 103-203.

REVILLA, M. ${ }^{a}$ L. 1985, Carta arqueológica de Soria: Tierra de Almazán. Soria.

REVILLA, R. et alii 1962, Excavaciones en la villa romana del Cercado de San Isidro, parcela «villa Posidica» (Dueñas, Palencia). Madrid.

TARACENA, B. 1950, «Las invasiones germánicas en España durante la segunda mitad del siglo III», en I Congreso internacional de Pirenaístas. Zaragoza.

TARRADELL, M. 1955, «Sobre las invasiones germánicas del siglo III d. C. en la Península Ibérica», en Estudios Clási$\cos$ III, n. ${ }^{\circ} 15,95-110$.

- 1957, «Problemas cronológicos de las invasiones germánicas del siglo III d. C.», en IV CNA (Burgos), Zaragoza, 231-239.

WATTEMBERG, F. 1962, «El mosaico de Diana en la villa de Prado (Valladolid)», en $B S A A$ XXVIII, 35ss. 